\title{
Structural impairments of the heart associating with ETB mutation, a cause of Hirschsprung disease
}

Ko-Chin Chen ( $\nabla$ ckochin@gmail.com )

Australian National University https://orcid.org/0000-0002-6650-1807

Ko-Chien Chen

University of Texas MD Anderson Cancer Center UTHealth Graduate School of Biomedical Sciences

\section{Zan-Min Song}

Australian National University

Geoffrey David Croaker

Australian National University

Research article

Keywords: Hirschsprung disease, heart defects, Endothelin-B mutation, spotting-lethal rat.

Posted Date: July 15th, 2020

DOI: https://doi.org/10.21203/rs.3.rs-34298/v1

License: @ (i) This work is licensed under a Creative Commons Attribution 4.0 International License.

Read Full License 


\section{Abstract}

Background HSCR, a colonic neurocristopathy affecting 1/5000 births, was suggested to associate with cardiac septal defects and conotruncal malformations. However, we question subtle cardiac changes maybe more commonly present due to multi-regulations by HSCR candidate genes, in this instance, $\mathrm{ET}_{\mathrm{B}}$. To investigate, we compared the cardiac morphology and quantitative measurements of $\mathrm{s} / \mathrm{s} /$ rat to those of the control group.

Methods Eleven neonatal rats were generated from heterozygote $\left(\mathrm{ET}_{\mathrm{B}}{ }^{+/-}\right)$crossbreeding. Age and bodyweight were recorded at time of sacrifice. Diffusion-staining protocols with $1.5 \%$ iodine solution was completed prior to micro-CT scanning. All rats were scanned using an in vivo micro-CT scanner, Caliper Quantum FX, followed by two quality-control scans using a custom-built ex vivo micro-CT system. All scans were reviewed for gross cardiac dysmorphology. Micro-CT data were segmented semiautomatically post-NLM filtering for: whole-heart, LV, RV, LA, RA, and aortic arch. Measurements were taken with Drishti. Following image analysis, PCR genotyping of rats was performed: five $s / / s /$ rats, three wildtype, and three heterozygotes. Statistical comparisons on organ volume, growth rate, and organvolume/bodyweight ratios were made between $s / / s /$ and the control group.

Results Cardiac morphology and constituents were preserved. However, significant volumetric reductions were recorded in $s / / s /$ rats with respect to the control: whole heart $(38.70 \%, p$-value $=0.02)$; LV $(41.22 \%, p$ value $=0.01), \operatorname{RV}(46.15 \%, p$-value $=0.02), \mathrm{LA}(44.93 \%, p$-value $=0.06)$, and RA $(39.49 \%, p$-value $=0.02)$. Consistent trend was observed in growth rate ( 20\%) and organ-volume/bodyweight ratios ( $25 \%)$. On the contrary, measurements on aortic arch demonstrated no significant difference among the two groups.

Discussion Despite the presence of normal morphology, significant cardiac growth retardation was detected in $s / / s /$ rat, supporting the likely association of cardiac anomalies with $\mathrm{HSCR}$, at least in $\mathrm{ET}_{\mathrm{B}^{-/-}}$ subtype. Structural reduction was likely due to a combination of failure to thrive from enteric dysfunction, alterations to CaNCC colonization, and importantly coronary hypoperfusion from elevated ET-1/ET $\mathrm{A}^{-}$ mediated hypervasoconstriction. Little correlation was detected between aortic arch development and $s / / s /$ rat, supporting minor $\mathrm{ET}_{\mathrm{B}}$ role in large vessels. Although further clinical study is warranted, $\mathrm{HSCR}$ patients may likely require cardiac assessment in view of congenital cardiac defects.

\section{Background}

\section{Highlights:}

- $\mathrm{ET}_{\mathrm{B}}^{-/-}$-HSCR was associated with body-growth impairment; neonatal $s / / s /$ rat has $16 \%$ less bodyweight than the control group.

- $s / / s /$ rat has grossly normal cardiac morphology. 
- Significant reductions were detected in cardiac structures of $s / / s /$ rats: $40 \%$ in whole-heart volume, $20 \%$ in growth rate, and $25 \%$ in whole-heart/bodyweight ratios. Similar trend was seen with LA, LV, RA, and RV.

- No consistent correlation was observed between $\mathrm{ET}_{\mathrm{B}}$ genotype and aortic arch sizes.

- These findings supported HSCR patients may have various degrees of neonatal cardiac anomalies; wholistic post-operative care should be considered.

- In consideration of the result of this paper, genotyping study of patients with and without heart failure would be an interesting step study to evaluate possible correlation between $\mathrm{ET}_{\mathrm{B}}$ genotype and risks of hypertension, ischemic heart disease, exercise capacity, and heart failure.

Hirschsprung's disease (HSCR), also known as "dilatation and hypertrophy of colon," was first popularized by Dr. Harald Hirschsprung in 1888 (1). HSCR is a pediatric intestinal aganglionic disease affecting $1 / 5000$ births globally but regional incidence may range from $1 / 1370$ to $1 / 7165$ births (2-5). Although the exact mode of HSCR inheritance is yet to be confirmed, the current view supports nonMendelian pattern with variable penetrance (6). However, this is likely due to multi-genetic involvement with confounding expression pattern. Overall, it has an 4: 1 male predominance (7). With up to $80-90 \%$ of cases diagnosed in the neonatal stage, it is commonly known for its clinical manifestations of pseudoobstruction and associated complications (8). HSCR is commonly treated with resection of variable lengths of hypoganglionic and aganglionic intestinal segments to avoid potential toxic megacolon $(7,9)$.

The pathogenesis of HSCR involves the migration failure of enteric neural crest cells (ENCC) to the growing gastrointestinal (GI) tract. Consequently, disrupted developments of myenteric and submucosal plexuses result in variable lengths of hypoganglionic and aganglionic colon (10). Similarly, HSCR associated congenital heart defects, particularly conotruncal heart malformations, can also arise from interruption of cardiac neural crest cells (CaNCC) migration (11-13).

During embryogenesis, the neural crest and its derivatives are under strict regulatory control by several genes, which become the potential targets for maldevelopment. In the case of HSCR, common causes include receptor tyrosine kinase (RET), glial cell line derived neurotrophic factor (GDNF), glycosylphosphophatidylinositol-linked receptor (GFRa1), ET-3, and $\mathrm{ET}_{B}$ (14-19). Under normal circumstance, GDNF/GFRa1/RET pathway provides the mitogenic drive for GDNF-dependent progenitors, which are responsible for the normal development of all enteric neurons $(20,21)$. Concomitantly, endothelin-3/endothelin-B receptor signaling $\left(E T-3 / E T_{B}\right)$ maintains the migration and the pluripotency of ENCC. In the event of $\mathrm{ET}_{\mathrm{B}}$ mutation, loss of $\mathrm{ET}^{-3} / \mathrm{ET}_{\mathrm{B}}$ stimulation results in premature differentiation of enteric neuron and thereby migration arrest as crest-derived neuronal precursors. Additionally, deficiency of ET-3/ET ${ }_{B}$ retards smooth muscle development and causes intestinal accumulation of laminin-1, which promotes premature-differentiation of enteric neurons through its $a_{1}$-subunit $(22,23)$. On the other hand, cardiac outflow tract development is dependent on the colonization by CaNCC, which is controlled by endothelin-1/endothelin-A receptor signaling $\left(E T-1 / E_{A}\right)(24,25)$. While no common regulatory pathways 
have been known to directly control both CaNCC and ENCC migration during embryogenesis, $\mathrm{ET}_{\mathrm{B}}$ may

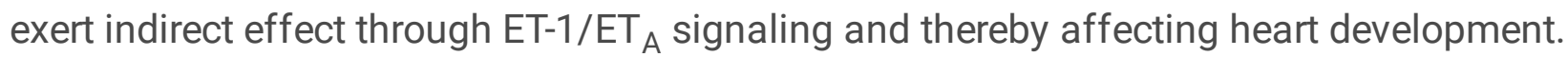

Clinically, this "not-so-conspicuous" relationship between heart malformation and HSCR is supported by a number of well documented syndromes (26). Indeed, recent studies have suggested multiple organ systems are affected in HSCR patients due to the pleomorphic effects of multi-genetic involvement in HSCR etiology (27-29). Up to $30 \%$ of HSCR patients are associated with abnormalities in the central nervous, gastrointestinal, genitourinary, endocrinological, immunological, and cardiovascular systems. These abnormalities are typified by some of the serious clinical syndromes, including: Down's syndrome (up to $2-10 \%$ of HSCR cases), Di George syndrome, Haddad syndrome, Mowat-Wilson syndrome, Type IV Waardenburg syndrome (WS-IV), and McKusick-Kauffman syndrome (MKKS). All of which are known to exhibit potential features of cardiac defects associating with $\operatorname{HSCR}(7,26,27,30,31)$. Additionally, conotruncal heart malformations associating with HSCR were also noted, atrioseptal defect (ASD; $2.2 \%$ ) and ventricular septal defect (VSD; 1.7\%) in particular. These reports support HSCR causation genes may have additional impacts on embryological heart development (32-34).

Although it was reported that up to $50 \%$ of familial and $30 \%$ of sporadic HSCR cases were due to mutation in RET and GDNF pathways whilst only $5 \%$ of HSCR were attributed to ET-3/ET ${ }_{B}$ signaling defects (35-37), we suspect $\mathrm{ET}_{B}$ 's importance may be underestimated. Indeed, recent studies from Taiwan (38), China (39), and Korea (40) demonstrated various novel mutations including p.P383_L386delinsP, D241D (c723T>C), N426N (c1278T>C), IVS4-14T>C, L227L (c831A>G), promoter-116C>T, 5'UTR-121G>T, IVS4+62C>A, and IVS5+121G>C in the $\mathrm{ET}_{\mathrm{B}}$ gene, adding additional mutation locus to existing data. Furthermore, Puffenberger et al (1994) also demonstrated significant increased risks for HSCR development from homozygous and heterozygous W276C missense mutations in $\mathrm{ET}_{B}$ genes, $74 \%$ and $21 \%$ respectively. These evidences suggested the possibility of dose-dependent $\mathrm{ET}_{B}$ effect and the likelihood of higher-than-quoted $\mathrm{ET}_{\mathrm{B}}$ mutation prevalence (41).

Among the causes of $\mathrm{HSCR}, \mathrm{ET}_{\mathrm{B}}$ is perhaps the most interesting due to its wide distribution, conflicting evidence of functions, and the strong vasoregulatory importance of endothelin-systems. $E T_{B}$ is a Gprotein-coupled heptahelical receptor sharing the same class as $\mathrm{ET}_{\mathrm{A}}(42)$. It is expressed in the central nervous system (CNS: medulla oblongata, cerebrum, hippocampus, cerebellum, striatum), gastrointestinal (Gl; enteric nervous systems), sensory organs (retina and stria vascularis), and cardiovascular systems (CAS: endocardium and coronary arterial endothelium) (28).

Both $\mathrm{ET}_{\mathrm{A}}$ and $\mathrm{ET}_{\mathrm{B}}$ initiate downstream signaling through respective binding with endothelin of different affinity.

Endothelin (ET) was first discovered in 1988 (43). In mammals, ET is first generated in the forms of preproendothelin followed by furin (prohormone convertase)-mediated cleavage to form inactive bigendothelin (44). Subsequently, big-endothelin is metabolized by endothelin converting enzymes-1 or -2 (ECE-1 or -2) to yield 21 amino-acids peptides of 3 classes: ET-1, ET-2, and ET-3 (45-47). ET-3 is 
responsible for the proliferation of pluripotent neural crest cells (NCCs) through its interaction with $\mathrm{ET}_{\mathrm{B}}$ to ensure normal intestinal development. ET-1 and ET-2 exert their function mainly in cardiovascular system.

Both $\mathrm{ET}_{\mathrm{A}}$ and $\mathrm{ET}_{\mathrm{B}}$ have high affinity to $\mathrm{ET}-1$ for vascular control (48); however, little is known about the structural impact from these interactions. Although subjects with $\mathrm{ET}_{\mathrm{B}}$ mutation are compatible with life (46), loss of $\mathrm{ET}_{\mathrm{A}}$ function results in severe craniofacial and cardiac defects due to migration failure of cephalic neural crest cell (CNCC) and CaNCC; neonatal mortality can therefore be high (25).

$\mathrm{ET}_{\mathrm{B}}$ 's cardiovascular effects are two-folds, mediating both vasodilation and vasoconstriction through the binding with ET-1 (49-52), the principal isoform in the cardiovascular system. It is secreted by the vascular endothelial cells and endocardial cells of cardiomyocytes $(53,54)$. Several studies have demonstrated that activation of ET-1/ET $\mathrm{B}$ pathway yields vasodilation via nitric oxide (NO), prostacyclin, and endothelium-relaxing factor (EDRF) thus balancing the vasoconstriction mediated by ET-1/ET $\mathrm{A}$ in vascular smooth muscle cells (VSMC). This suggested $\mathrm{ET}_{\mathrm{B}}$ may have a beneficial role in myocardial circulation (55-57). Indeed, additional support was shown by the increased vasoconstriction observed in endothelium-denuded coronary artery (58). By the same token, one would expect HSCR patients with homozygous $\mathrm{ET}_{\mathrm{B}}{ }^{-/-}$mutation to have impaired cardiovascular development and subsequently higher risks for hypertension, coronary artery disease, and congestive heart failure $(59,60)$.

Although a number of microscopic and physiologic studies have been conducted to determine the functions of $E T_{B}$ receptor, to the best of our knowledge, no macroscopic analyses have been completed on the effect of the $\mathrm{ET}_{\mathrm{B}}$ gene on cardiac anatomy $(28,52,61,62)$. We aim to complement this knowledge by quantitatively analyzing the cardiac anatomy of the spotting-lethal $(s / / s)$ rat, a naturally occurring $\mathrm{ET}_{\mathrm{B}}{ }^{-/-}$animal model of WS-IV, with the appearance of HSCR, hearing deficits, and white coat color (63). Based on our segregation analysis, $s / / s /$ rat follows autosomal recessive inheritance $(p$-value $=0.001)$ with high genetic penetrance, up to $95 \%$ of $s / / s /$ rats exhibited HSCR. Conversely, incidence of rare mutant phenotype was seen in less than $3 \%$ of the control group, which consisted of the wild-type and heterozygotes. Consequently, statistical comparison in this study was made between $s / / s /$ and control groups.

To achieve detailed yet structurally preserved anatomical information, we adopted X-ray micro-computed tomography (micro-CT) with modified tissue-staining techniques (64). Micro-CT offers three-dimensional (3D) information with high-resolution images comparable to the low powered 2D microscopy, allowing detailed quantitative analysis. In addition, improvement on imaging analysis software in recent years have rendered detection of subtle volumetric and dimensional changes in cardiac system possible.

In this study, we hypothesize the following:

1. $\mathrm{ET}_{\mathrm{B}}{ }^{-/-} \mathrm{HSCR}$ model, $s / / s /$ rat, exhibits minor body-growth impairment in early age. 
2. Gross cardiac morphology may be preserved in $s / / s /$ rat from intact ET-1/ET $A$

3. However, loss of functional $\mathrm{ET}_{\mathrm{B}}$ gene may be associated with reduced heart size, growth rate, and heart-volume/bodyweight ratio.

4. Cardiac growth may be $\mathrm{ET}_{\mathrm{B}}$-dose-dependent.

5. Absence of functional $\mathrm{ET}_{\mathrm{B}}$ has little effect on aortic arch growth.

\section{Methods}

\subsection{Compliance with Ethical practice}

All tissues and animals used in this study were handled with care and strict compliance to ACT Health Human Research Ethics Committee (ACTH-HREC) and Australian National University Animal Experimentation Ethics Committee (ANU-AEEC), ethic approval project number A2011/67.

\subsection{Method of euthanasia}

In this study, the rat specimens were generated through from crossbreeding among the heterozygous $\left(\mathrm{ET}_{\mathrm{B}}^{+/-}\right)$parents. This breeding colony originally derived from natural-occurring mutation and has been maintained in Australian National University (ANU) over the past 15 years.

Eleven neonatal rats with an average age of 88 hours were sacrificed. Individual rat's coat pattern, age, gender, and weight were recorded. These rats were over anaesthetized with $5 \%$ isoflurane for $15 \mathrm{minutes}$ in modified gas chamber prior culling. These rats were culled via abdominal aortotomy following a midline laparotomy of $1 \mathrm{~cm}$ using scalpel and iris scissor. Five-millimeter tail-tip of each rat was resected and stored for subsequent genotyping.

\subsection{Tissue preparation and staining}

For successful micro-CT scanning, diffusion staining was performed through the following steps. Firstly, midline thoracotomy of one centimeter was performed to facilitate tissue penetration into cardiac tissue by the staining solution. The thoractomized bodies were immersed in 10\% PBS solution for 30 minutes to wash out residual body fluid followed by fixation in $4 \%$ formalin solution for 24 hours. Next, formalin was washed out with graded ethanol (EtOH) series: $20 \%, 50 \%, 70 \%$, and $90 \%$ for 1 day each. Lastly, these EtOH-fixed tissues were stained with $1.5 \%$ iodine (in $90 \%$ EtOH) for a minimum of seven days prior to micro-CT scanning.

\subsection{Image acquisition by micro-CT scanning}

Current micro-CT systems are generally classified into in vivo and ex vivo based on system setups; these terminologies are not related to their standard definitions in biomedical science but rather as descriptions of the system setups (65). In vivo micro-CT scanner incorporates a stationary sample positioned in between a rotational system of $x$-ray source and detector. On the contrary, ex vivo micro-CT system 
involves a rotational sample situating in between the adjustable x-ray source and detector; this setup can yield a higher magnification image by shortening the distance between the sample and x-ray source (66, 67). Furthermore, it can generate high signal-to-noise ratio image by prolonging the scanning time.

In this study, a commercial in vivo micro-CT scanner, Caliper Quantum FX, has been chosen to acquire the scans of all tissues whereas ex vivo micro-CT scans were derived from a custom-built micro-CT system by ANU Applied Mathematical Department. The maximal resolution achievable by Caliper Quantum FX was $10 \mu \mathrm{m} /$ voxel with an efficiency of 4.5 minutes per scan. The average dataset size was $256 \mathrm{MB}$. The resultant images were stored as DICOM series and visualized with FIJI and Drishti, both of which were open-source software $(68,69)$. On the other hand, the custom-built ex vivo micro-CT system in ANU Applied Mathematical Department required at least 15 hours of scanning time with additional 8 hours of image-processing time via National Computational Infrastructure $(\mathrm{NCl})$ services. The maximal resolution was $1 \mu \mathrm{m} /$ voxel, limited by the physical size of the sample. The resultant images were stored as netCDF files and visualized with Drishti (68). Each dataset has an average size of $12-16$ GB.

Due to limited access to the ex vivo micro-CT scanners, all image data acquired by Caliper Quantum FX were processed with non-local means (NLM) algorithms to improve image quality (70). To ensure adequate anatomical details and image quality of denoised in vivo micro-CT data were suitable for quantitative analysis, two sets of ex vivo micro-CT data were acquired for quality control. Although not ideal, we found in vivo micro-CT scans offered sufficient macroscopic anatomical details for the purposes of this study.

\subsection{Image segmentation and analysis}

Acquired micro-CT data were first denoised using NLM algorithm to improve signal-to-noise ratio and hence image clarity for segmentation (70). This code was implemented on an Intel (R) Core ${ }^{\mathrm{TM}}$ i7-4770K CPU @3.5GHz system with 32G of RAM and Nvidia GeForce GTX Titan Black Kepler GK110 architecture running Linux.

Following image filtering, micro-CT data were segmented semi-automatically through individual CT slices for selected organs using Drishti (68). The following cardiac organs were isolated for quantitative measurements: whole heart, left atrium (LA), left ventricle (LV), right atrium (RA), right ventricle (RV), and ascending aortic arch (AA). This process was repeated for each structure. Segmentation of the whole heart was first completed to determine possible gross cardiac defects associating with the mutants. Twodimensional (2D) measurements of LA, LV, RA, and RV were then taken in coronal views where maximal width and length of each structure were measured. The luminal width of AA was measured at the aortic orifice in axial view for standardize comparison. Finally, three-dimensional (3D) volumetric measurements were completed following sub-segmentation of each structure.

To standardize comparison, the following anatomical definitions were adopted. The pulmonary circulatory inflow was defined by the superior and inferior vena cava orifices to right atrium; the outflow was defined by the pulmonary valve. The systemic circulatory inflow was defined by pulmonary vein 
orifices to the left atrium whereas the outflow was defined by the aortic valve. Both selections of left and right ventricles have included interventricular septal wall for clear definition of organ boundary for better comparison. Lastly, for the comparison of AA, the boundary of AA was defined as arterial vessel between the aortic valves to the first branching point, brachiocephalic artery.

\subsection{H\&E light microscopy}

H\&E light microscopy was completed for two of eleven rats following micro-CT scanning to assess cardiac anatomical details presented by micro-CT scans. The following steps were performed. The iodinestained hearts were sectioned longitudinally into blocks of $4 \mathrm{~mm}$ in thickness and placed in cassettes. Contrast washout and dehydration were performed in $90 \% \mathrm{EtOH}$ for 48 hours prior to paraffin embedment at $60^{\circ} \mathrm{C}$. These tissue blocks were then sliced to $4 \mu \mathrm{m}$ thick tissue-sheets with a microtome. Tissue-sheets were then laid in water-bath of $5-6^{\circ} \mathrm{C}$ while being positioned onto labelled-glass slides. These slides were dried overnight at $37^{\circ} \mathrm{C}$.

Progressive H\&E staining was completed by placing the slides in alum-hematoxylin solutions until the appearance of dark red color. Washing and 'bluing' with lithium carbonate solution were then performed. Lastly, washing and counter-staining with $0.5 \%$ eosin alcoholic solution were completed.

All H\&E slides were reviewed with an Olympus IX71 microscope with 4x magnification.

\subsection{Genotyping}

After the completion of quantitative data analysis, genotyping was completed as described below. Three homozygous wild-type $\left(\mathrm{ET}_{\mathrm{B}}^{+/+}\right)$, three heterozygous $\left(\mathrm{ET}_{\mathrm{B}}{ }^{+/}\right)$, and five homozygous spotting lethal ( $\mathrm{sl} / \mathrm{sl}$; $\left.\mathrm{ET}_{\mathrm{B}}{ }^{-/}\right)$rats were identified. The average ages of wild-type, heterozygous, and homozygous mutant rats were 90.7 hours, 96 hours, and 83.2 hours respectively.

PCR genotyping was completed through the following protocols. Five-millimeter tail tips of the eleven rats were lysed using Proteinase $\mathrm{K}$ in lysis buffer consisting of $100 \mathrm{mM}$ Tris $\mathrm{pH} 8,5 \mathrm{mM}$ EDTA, $0.2 \%$ SDS, and $200 \mathrm{mM} \mathrm{NaCl}$ in distilled water. The DNA was extracted via vortex heating and centrifuging to separate the DNA-containing supernatants from undigested materials. The supernatants were further vortexed and centrifuged to isolate the DNA pellets. The DNA pellets were then washed with $70 \% \mathrm{EtOH}$ and dried. The DNA was then suspended and quantified using spectrophotometry. Next, PCR was completed with "Master-Mix" reagent, which included: 10*PCR buffer Qiagen-contained $\mathrm{MgCl}_{2}$, dNTP (10mM), Primer PS7

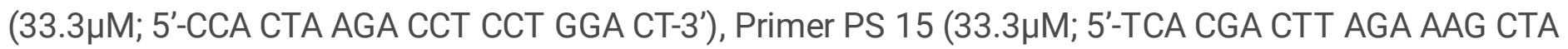
CAC T-3') and DNA polymerase (71). Afterward, the Master-Mix reagent was pipetted onto PCR plates filled with the 11 rat DNAs followed by PCR in Veriti 96-Well Thermal-Cycler. Finally, electrophoresis of fourteen DNA samples (eleven test-subject DNA, one proven wild-type, one heterozygote, and one $s / / s /$ rat) was run for one hour under the voltage setting of $100 \mathrm{~V}$ and current setting of $55 \mathrm{~mA}$, with MassRuler (\#SM1263, Fermentas) reference by the side. The resultant electrophoresis gel was visualized with Gel Documentation System DOC-Print VX5 (Vilber Lourmat). 


\subsection{Comparing and Statistical analysis}

Based on the strong autosomal-recessive trait and high genetic penetrance of $s / / s /$ rats, statistical comparison using the two-tail t-test was made between the $s / / s /\left(\mathrm{ET}_{\mathrm{B}}^{\left.-{ }^{--}\right)}\right.$and the control group $\left(\mathrm{ET}_{\mathrm{B}}{ }^{+/+}\right.$\& $\left.\mathrm{ET}_{\mathrm{B}}{ }^{+/}\right)$to determine the $\mathrm{ET}_{\mathrm{B}}$ effect on heart growth. The comparisons were made in the parameters of organ size, organ growth rate, and organ-volume/bodyweight ratios. Albeit small, the latter two were made to exclude the effect of individual rat's age and body-size variations for comparison. Additionally, these parameters provided information on the rate of changes with respect to age and body-size thereby enabling estimation of the structural changes upon developmental maturation.

The difference (\%) between the control and $s /$ s/ groups were calculated for each parameter. Additionally, the proportionality of individual cardiac substituent with respect to the whole heart (organ/heart ratio) were compared to explore potential regional-dependent effect. Lastly, data of respective wild-types $\left(\mathrm{ET}_{\mathrm{B}}^{+/+}\right)$and heterozygotes $\left(\mathrm{ET}_{\mathrm{B}}^{+/}\right)$were provided in the supplementary figures for illustrations of possible gene-dose-dependent relationship.

\section{Results}

\subsection{Reduced body-size and body growth rate in sl/sl rat}

Based on our measurements of neonatal rats, $\mathrm{ET}_{\mathrm{B}}$ mutation was associated with minor changes in bodysize and body growth rate, at least from the age of eighty hours. As shown by Figure $1 \mathrm{a}, \mathrm{sl} / \mathrm{sl}\left(\mathrm{ET}_{\mathrm{B}}{ }^{\left.-{ }^{-}\right)}\right.$) rats have $16.32 \%$ smaller bodyweight of than that of control group, $p$-value $=0.03$. On the other hand, when standardized to rats' age, this difference was only $3.53 \%, p$-value $=0.577$, as shown by Figure $1 \mathrm{~b}$. Although not shown, there was little variability in bodyweight and body-growth between the wild-type $\left(\mathrm{ET}_{\mathrm{B}}^{+/+}\right)$and heterozygotes $\left(\mathrm{ET}_{\mathrm{B}}^{+/-}\right)$, suggesting the absence of $\mathrm{ET}_{\mathrm{B}}$ dose-dependent relationship.

\section{$3.2 \mathrm{sl} / \mathrm{sl}$ rat has grossly normal cardiac morphology}

Previous studies have suggested disruptions in the endothelin system lead to CaNCC migration failure and cause cardiac outflow tract defects (24). Thorough reviews of the eleven rat micro-CT scans did not reveal marked gross change in cardiac morphology. As typified by the sectional micro-CT slices and H\&E scan shown in Figure 2, sl/s/ heart possessed all the essential components of a normal heart: aorta, aortic semilunar valve, right and left atrium, right and left ventricles, intact interatrial and interventricular septum, and patent pulmonary vessels. Expectedly, cardiac anatomy of wild-type and heterozygous rats shared the same features. This preliminary finding suggested $\mathrm{ET}_{\mathrm{B}}$ may have little impact on CaNCC migration. On the other hand, 2D measurements have showed subtle reductions in width and lengths of cardiac structures in $s / / s /$ rat.

\subsection{Quantitative Difference - Volumetric measurements $\left(\mathrm{mm}^{3}\right)$}


Following the morphological examinations, volumetric measurements were performed for quantitative comparison. Our data demonstrated homozygous $\mathrm{ET}_{\mathrm{B}}$ mutation was associated with significant volumetric reductions in the heart and constituents.

As demonstrated by Figure 3, sl/s/ rat has a statistically significant smaller heart than the control group, up to $38.7 \%$ reduction, $p$-value $=0.02$. Similar changes were also observed in the following constituents: LV $(41.22 \%, p$-value $=0.01), \operatorname{RV}(46.15 \%, p$-value $=0.02)$, LA $(44.93 \%, p$-value $=0.06)$, and RA $(39.49 \%, p$ value $=0.02)$. Volumetric measurement of AA also showed $22.00 \%$ reduction in $s / / s /$ rats with respect to the control, albeit this finding did not reach statistical significance, $p$-value $=0.25$.

Additionally, while not reported by current literature, a potential $\mathrm{ET}_{\mathrm{B}}$ dose-dependent impact on cardiac size may be appreciated. As shown by Supplementary Figure 1, wild-type rat has the largest heart among the three genotypes, followed by heterozygote in the middle and $s / / s /$ rat in the last. Concordantly, LA, RA, LV and RV measurements of wild-types were $42.76 \%-48.09 \%$ larger than those of $s / / s /$ rats, whereas those of heterozygotes were only $34.71 \%-44.71 \%$ larger.

Overall, we showed neonatal $s / / s /$ rats having approximately $40 \%$ smaller hearts with respect to the control group. These differences may continue to widen with age until rats reach maturation.

\subsection{Quantitative Difference - Organ growth rate measurements $\left(\mathrm{mm}^{3} / \mathrm{Hr}\right)$}

To determine the temporal effect of $\mathrm{ET}_{\mathrm{B}}$ mutation on growth during development, we compared the cardiac growth rates of $\mathrm{s} / \mathrm{s} /$ and the control groups. As shown by Figure 4 , the growth rate of whole heart in $s / / s /$ rat was $23.70 \%$ lower than that of control group, $p$-value $=0.05$. Significant reducing trends were also observed in the growth rates of $\operatorname{LV}(26.39 \%, p$-value $=0.02)$ and $\operatorname{RV}(31.25 \%, p$-value $=0.03)$. Additionally, although not reaching the statistical power, reductions in LA $(27.36 \%, p$-value $=0.18), \mathrm{RA}$ $(23.42 \%, p$-value $=0.10)$ and $\mathrm{AA}(9.28 \%, p$-value $=0.51)$ were also recorded in the $s / / s /$ rats.

Further analysis showed a stepwise reducing trend in organ growth rates with decreasing copies of functional $\mathrm{ET}_{\mathrm{B}}$ gene. As shown by Supplementary Figure 2, the LA, RA, LV, and RV growth rates of heterozygous rats were $17.40 \%-26.60 \%$ larger than those of $s / / s /$ rats, whereas those of wild-types were in the ranges of $29.43 \%-35.91 \%$. On the other hand, analyses on AA growth rates demonstrated no consistent correlations with $\mathrm{ET}_{\mathrm{B}}$ dose.

Overall, a trend of approximately $25 \%$ decrease in cardiac growth rate across all heart constituents could easily be appreciated in neonatal $s / / s /$ rats. These impairments may persist until rat maturation. Interestingly, this reduction was disproportionally larger than the $3.53 \%$ reduction in the bodyweight growth rates, suggesting an intrinsic effect of $\mathrm{ET}_{\mathrm{B}}$ to the developing heart.

\subsection{Quantitative Difference - Organ-volume/bodyweight ratio comparison $\left(\mathrm{mm}^{3} / \mathrm{g}\right)$}


Disproportionally larger impact of $\mathrm{ET}_{\mathrm{B}}$ mutation on heart structures with respect to its effect on body size was illustrated by the cardiac organ-volume/bodyweight comparison between the $s / / s /$ and control groups. As previously shown, both heart organ-volume and bodyweight of $s / / s /$ rats shared a decreasing trend. Figure 5 showed $s / / s /$ rat having approximately $20 \%$ smaller organ-volume/bodyweight ratios than those of control group in the following: whole-heart $(20.00 \%, p$-value $=0.04), \operatorname{RA}(20.79 \%, p$-value $=0.05)$, $\operatorname{LV}(21.75 \%, p$-value $=0.03)$, and RV $(26.54 \%, p$-value $=0.04)$. Additionally, although not achieving statistical significance, LA-volume/bodyweight ratio of $s / / s /$ rat also has a reduction of $25.75 \%, p$-value $=$ 0.13. Overall, homozygous $\mathrm{ET}_{\mathrm{B}}$ mutation was associated with a disproportionally larger reduction in cardiac sizes with respect to changes in global body size. This was further supported by a stepwise decreasing pattern with reducing copies of functional $\mathrm{ET}_{\mathrm{B}}$ gene, as illustrated by Supplementary Figure 3 . On the other hand, little change was detected in AA measurements, with $s / / s /$ rat having $5.17 \%$ larger AA than that of control group, $p$-value $=0.70$, an observation consistent with $\mathrm{ET}_{\mathrm{B}}$ 's minor regulatory role on large vessel.

\subsection{Regional dependency - Organ/whole heart ratio comparison}

To explore potential regional variation on the structural impacts associating with $\mathrm{ET}_{\mathrm{B}}$ mutation, we compared the cardiac constituent/whole-heart ratios between $s / / s /$ and the control group, as showed by Figure 6. Overall, little difference between the two groups was observed, albeit slight reduction up to $5.81 \%$ was detected in RV/whole-heart ratio.

\section{Discussion}

In this study, we demonstrated neonatal HSCR animal model exhibiting significant cardiac growth impairment. This was consistently illustrated in three parameters of rats with an average age of 88 hours: up to $40 \%$ reduction in heart volume, $20 \%$ reduction in growth rate, and $25 \%$ reduction in organvolume/bodyweight ratios. The causes for these cardiac growth restrictions likely involved three factors: global growth impairments due to enteric dysfunction; alterations in CaNCC development; vasodysregulation by the absence of $\mathrm{ET}_{\mathrm{B}}$.

Up to $30 \%$ of HSCR patients exhibit developmental anomalies. Congenital heart diseases (CHD) accounted for $5-8 \%$ (72). While only $3 \%$ of CHD occurred in non-syndromic HSCR infants, the prevalence of $\mathrm{CHD}$ associated with chromosomal HSCR patients was remarkably high, ranging from 20 to $80 \%$, with cardiac septal defects being the most common anomalies (26). Furthermore, regional pediatric data on HSCR patients with associated Down's syndrome (HSCR/DS) also demonstrated that up to $48 \%$ suffered CHD; such a high concurrence therefore suggested DS could be a major risk factor for CHD in HSCR children (73). Accordingly, our findings recorded HSCR model having significant reductions in heart development despite the manifestation of normal morphology, suggesting that HSCR patients, at least in $\mathrm{ET}_{\mathrm{B}}{ }^{-/-}$variant, likely to suffer heart growth impairments and predisposition to cardiovascular diseases. This also supported the notion that CHD incidence in HSCR may be underestimated due to underreporting of subtle cardiac anomalies. 
Homozygous $\mathrm{ET}_{\mathrm{B}}$ gene knock-out $\left(\mathrm{ET}_{\mathrm{B}}^{-/-}\right)$results in WS-IV with prominent $\mathrm{HSCR}$ phenotypes. As previously mentioned, aberrant mutation in $\mathrm{ET}-3 / \mathrm{ET}_{\mathrm{B}}$ signaling causes migration failure of ENCCs and subsequent developmental failure of ENS (18). Consequently, we observed $16.53 \%$ decrease in bodyweight or $3.42 \%$ decrease in body growth-rate of $s / / s /$ rats, Figure 1 . This global reduction likely has contributed, at least partially, to the cardiac impairment recorded. Concordantly, this impairment may likely worsen with age as the manifestation of enteric failure becomes more prominent.

Additionally, we acknowledged that cardiac growth impairment may be partially contributed by the migration failure of $\mathrm{CaNCC}$, potentially due to failure of overlapping control by $\mathrm{ET}-3 / \mathrm{ET}_{\mathrm{B}}$ signaling although this was not well documented. On the other hand, alteration in ET-1/ET $A$ signaling by elevated ET-1 levels in $s / / s /$ rat likely played an important role. Indeed, mice with ET-1/ET ${ }_{A}$ defects manifested with features like velocardiofacial syndrome (25) due to impaired CaNCC migration (24). It has been well documented that CaNCC colonizes cardiac outflow tract (OFT) and pharyngeal arches during embryogenesis $(12,74)$. CaNCC facilitated the remodeling of pharyngeal arch arteries (PAAs), which formed the bilateral carotid arteries, segment of aortic arches, pulmonary artery, and ductus arteriosus. Additionally, CaNCC affected large vessels developments (75). Consistently, removal of CaNCC during development resulted in inappropriate PAA regression, which caused type $b$ interrupted aortic arch in mouse models (12). Furthermore, prior studies demonstrated the presence of CaNCC enables cardiac OFT remodeling and facilitates cardiac septation in mouse (76) while the absence of CaNCC results in ventricular septal defects (VSDs) and abnormal aortic arch formation $(12,13)$. Nevertheless, neither large vessel nor septal anomalies were observed in the heart of in $s / / s l$, but significant structural reductions were found. While prior lineage-tracing studies did not reveal participation of CaNCC in the developments of mouse myocardium and epicardium (77), biomarker studies using P/xna2, fate-mapping, and the finding of thin ventricular myocardium as a result of CaNCC gene knock-out studies (e.g. BMPR1A and PAX3) suggested CaNCC contributes to mouse epicardial developments and ventricular myocardium (7880). Concordantly, our analysis showed marked cardiac atrial and ventricular shrinkage in $\mathrm{s} / \mathrm{s} / \mathrm{rat}$, supporting CaNCC pathway may partially contribute to direct myocardium development. Indeed, while ET1 elevation in $s / / s /$ rat may have not caused premature arrest of CaNCC colonization to cardiac OFT, subtle alteration to myocardium from hyperstimulation of $E T-1 / E_{A}$ is likely.

More importantly, $\mathrm{ET}_{\mathrm{B}}$ was a widely expressed receptor with vascular control. Indeed, its dual modes of actions in vascular systems suggest its loss-of-function could be detrimental to cardiac development. It has been documented that $\mathrm{ET}_{\mathrm{B}}$ was predominantly expressed in the vascular endothelium where it initiates vasodilation through binding with ET-1, which triggers decreased clearance of NO, prostacyclin, and EDRF. On the other hand, subtle $\mathrm{ET}_{\mathrm{B}}$ presence has also been demonstrated in VSMC, where ET-1 activations result in vascular constriction, albeit this effect was minor in normal physiological state (50, $55,56,81,82)$. Indeed, Nilsson et al (2008) have cleverly illustrated this functional duality of $\mathrm{ET}_{\mathrm{B}}$ through recordings of stronger vasoconstrictive response from the organ-culture of endothelium-denuded porcine coronary artery following stimulation by Sarafotoxin $6 \mathrm{c}(58)$. This showed endothelial $\mathrm{ET}_{\mathrm{B}}$ partially regulates baseline vasodilation and basal coronary perfusion, which was vital to the developing heart. 
Adding insult to injury, the absence of $\mathrm{ET}_{\mathrm{B}}$ markedly reduced the clearance of $\mathrm{ET}-1$, as supported by the 6folds increase of ET-1 level found in $s / / s /$ rats (83). This would lead to elevated ET-1/ET $A$ stimulation and subsequent hyper-vasoconstriction of coronary artery. Consequently, further hypoperfusion resulted in disproportional large growth retardation in heart, as shown by Figure 3 to 5 (84). Interestingly, the pattern of stepwise reduction in heart volume, growth rates, organ-volume/bodyweight ratios corresponded well with decreasing functional $\mathrm{ET}_{\mathrm{B}}$ copies, as shown by Supplementary Figure 1 to 3 . This was also consistent to the dose-dependent decreases in myocardial perfusion following ET-1 infusion to the coronary artery $(84,85)$. Furthermore, Figure 6 illustrated reduction in ventricular myocardium was slightly more prominent than that of atrial myocardium, which might reflect variance in rat coronary arterial distribution, albeit this regional difference was very small.

Lastly, 3D analyses made on aortic arch demonstrated no conclusive $\mathrm{ET}_{\mathrm{B}}$-dependent relationship, Figure 3 to 5 . On the other hand, subtle decrease in aortic luminal diameter was observed in $s / / s /$ rat, as noted by Supplementary Table 1. This reflected the likely elevated basal vasoconstriction at the time of culling, mediated by elevated ET-1/ET $A$ signaling. Additionally, this finding was consistent with the minor $\mathrm{ET}_{B}$ presence and the predominant $\mathrm{ET}_{\mathrm{A}}$-mediated contractile control in large vessels as reported previously $(49,86)$.

Overall, our result showed distinctive difference in cardiac growth between $s / / s /$ and the control groups. The effect of $E T_{B}$ on cardiogenesis was likely multifactorial rather than a pure manifestation of HSCR's poor growth (87). While we cannot be certain on the exact pathogenesis of $\mathrm{ET}_{\mathrm{B}}$ dysfunction leading to the cardiac reduction, in conjunction with prior studies, hypoperfusion from vascular dysregulation seems likely. Nevertheless, we acknowledged the possibility of growth impairment from enteric dysfunction and changes in CaNCC colonization to the developing heart, albeit these effects were likely minor if presented. Importantly, our finding provided a clue to the suspected cardiac impairment associated with HSCR, a traditionally thought surgical disease. Indeed, if this quantitative finding is translatable to human, HSCR patients are likely to suffer a significant cardiac structural reduction, ranging from $20 \%$ to $40 \%$, and thereby increases risk for development of cardiac failure, at least in the $\mathrm{ET}_{\mathrm{B}}{ }^{-/}$subtype. Consequently, a wholistic management may be warranted.

While we have demonstrated quantitative measurements of complex organs using micro-CT and subsequent imaging analyses, traditional dimensional measurements of cardiac anatomy have also been attempted but deemed unsatisfactory due to the high variance in 2D measurements of complex morphology. Albeit tedious, 3D volumetric measurements following image segmentation provided a standardized structural comparison. We acknowledged the statistical power can be improved with higher sampling and further clinical study would be beneficial.

\section{Conclusion}


This study demonstrated a correlation between $\mathrm{ET}_{\mathrm{B}}$ function and cardiac size in the $s / / s /$ rat. The exact mechanism of action is unclear at this point but may well be due to an effect on coronary artery tone. Preserved cardiac morphology and aortic arch dimensions suggest impaired CaNCC migration failure may play little role in HSCR. Nevertheless, the finding of significant cardiac size and growth impairment in HSCR model is consistent with an elevated risk of congenital structural heart disease in HSCR patients. It also raises the possibility that $\mathrm{ET}_{\mathrm{B}}$ gene may have a role in the development of heart failure, coronary artery disease, and hypertension in the general population.

\section{List Of Abbreviations}

AA: aortic arch

ANU-AEEC: Australian National University Animal Experimentation Ethics Committee

ACTH-HREC: ACT Health Human Research Ethics Committee

ASD: atrioseptal defect

CaNCC: cardiac neural crest cell

CAS: cardiovascular system

CHD: congenital heart disease

CNCC: cephalic neural crest cell

CNS: central nervous system

DICOM: digital imaging and communications in medicine

DNA: Deoxyribonucleic acid

dNTP: Deoxynucleoside triphosphate

DS: Down's syndrome

GDNF: glial cell line derived neurotrophic factor

GFRa1: GDNF family receptor alpha 1

Gl: gastrointestinal

H\&E: hematoxylin and eosin stain

HSCR: Hirschsprung's disease 
ECE-1: endothelin converting enzyme-1

ECE-2: endothelin converting enzyme-1

EDRF: endothelium-relaxing factor

EDTA: Ethylenediaminetetraacetic acid

ENCC: enteric neural crest cell

ET-1: endothelin-1

ET-2: endothelin-2

ET-3: endothelin-3

$\mathrm{ET}_{\mathrm{A}}$ : endothelin-A receptor

$\mathrm{ET}_{\mathrm{B}}$ : endothelin-B receptor

EtOH: ethanol

LA: left atrium

LV: left ventricle

$\mathrm{MgCl}_{2}$ : magnesium chloride

Micro-CT: micro-computed tomography

MKKS: McKusick-Kauffman syndrome

$\mathrm{NaCl}$ : sodium chloride

NCC: neural crest cells

NCl: National Computational Infrastructure

NLM: Non-Local Means

NO: nitric oxide

OFT: outflow tract

PAA: pharyngeal arch artery

PCR: polymerase chain reaction 
$\mathrm{RA}$ : right atrium

$\mathrm{RV}$ : right ventricle

RET: proto-oncogene RET

sl/sl: spotting-lethal

3D: three-dimensional

2D: two-dimensional

VSD: ventricular septal defect

VSMC: vascular smooth muscle cell

WS-IV: Waardenburg-Shah syndrome

\section{Declarations}

Ethical approval and consent to participate

This research project was approved by both ACT Health Human Research Ethics Committee (ACTHHREC) and Australian National University Animal Experimentation Ethics Committee (ANU-AEEC), project number A2011/67.

Consent to publish:

Not applicable.

Availability of data and materials

Due to the significantly large micro-CT file size for public repositories, all datasets are stored in the National Computational Infrastructure (NCI) Australia and available upon request. Request may be sent directly to corresponding author at ckochin@gmail.com.

Competing interests:

We have no competing interests.

\section{Funding:}

None declared.

Author's contributions: 
Conceived the study: KC, KC, ZMS, GDH. Developed the methodology, performed the experiment and analysis: KC, ZMS, GDH. Performed the image analysis and statistical data analysis: KC, KC. Wrote the paper: KC, KC, GDH. All authors read and approved the final manuscript.

\section{Acknowledgements:}

The authors gratefully acknowledge the staff of Australian National University Applied Mathematic Department for their technical support of this project.

\section{Authors Information:}

Dr. Ko-Chin Chen is a clinician and a PhD candidate at medical School of Australian National University. Ms. Ko-Chien Chen is a PhD candidate at MD Anderson Cancer Centre of University of Texas.

Dr. Zan-Min Song is a senior lecturer at medical school of Australian National University.

Prof. Geoffrey D. Croaker is a professor at medical school of Australian National University and a staff specialist of Paediatric Surgery Department at the Canberra Hospital

\section{References}

1. Skaba R. Historic milestones of Hirschsprung's disease (commemorating the 90th anniversary of Professor Harald Hirschsprung's death). Journal of pediatric surgery. 2007;42(1):249-51.

2. Russell MB, Russell CA, Niebuhr E. An epidemiological study of Hirschsprung's disease and additional anomalies. Acta paediatrica (Oslo, Norway : 1992). 1994;83(1):68-71.

3. Goldberg EL. An epidemiological study of Hirschsprung's disease. International journal of epidemiology. 1984;13(4):479-85.

4. Rajab A, Freeman NV, Patton MA. Hirschsprung's disease in Oman. Journal of pediatric surgery. 1997;32(5):724-7.

5. Meza-Valencia BE, de Lorimier AJ, Person DA. Hirschsprung disease in the U.S. associated Pacific Islands: more common than expected. Hawaii medical journal. 2005;64(4):96-8, 100-1.

6. Butler Tjaden NE, Trainor PA. The developmental etiology and pathogenesis of Hirschsprung disease. Translational research : the journal of laboratory and clinical medicine. 2013;162(1):1-15.

7. Skinner MA. Hirschsprung's disease. Current problems in surgery. 1996;33(5):389-460.

8. Singh SJ, Croaker GD, Manglick P, Wong CL, Athanasakos H, Elliott E, et al. Hirschsprung's disease: the Australian Paediatric Surveillance Unit's experience. Pediatric surgery international. 2003;19(4):247-50.

9. Anderson RB, Stewart AL, Young HM. Phenotypes of neural-crest-derived cells in vagal and sacral pathways. Cell and tissue research. 2006;323(1):11-25. 
10. Whitehouse FR, Kernohan JW. Myenteric plexus in congenital megacolon; study of 11 cases. Archives of internal medicine (Chicago, III : 1908). 1948;82(1):75-111.

11. Kubalak SW, Hutson DR, Scott KK, Shannon RA. Elevated transforming growth factor beta2 enhances apoptosis and contributes to abnormal outflow tract and aortic sac development in retinoic $\mathrm{X}$ receptor alpha knockout embryos. Development. 2002;129(3):733-46.

12. Kirby ML, Gale TF, Stewart DE. Neural crest cells contribute to normal aorticopulmonary septation. Science. 1983;220(4601):1059-61.

13. Porras D, Brown CB. Temporal-spatial ablation of neural crest in the mouse results in cardiovascular defects. Developmental dynamics : an official publication of the American Association of Anatomists. 2008;237(1):153-62.

14. Ryan ET, Ecker JL, Christakis NA, Folkman J. Hirschsprung's disease: associated abnormalities and demography. Journal of pediatric surgery. 1992;27(1):76-81.

15. Badner JA, Sieber WK, Garver KL, Chakravarti A. A genetic study of Hirschsprung disease. American journal of human genetics. 1990;46(3):568-80.

16. Brooks AS, Oostra BA, Hofstra RM. Studying the genetics of Hirschsprung's disease: unraveling an oligogenic disorder. Clinical genetics. 2005;67(1):6-14.

17. Tansey MG, Baloh RH, Milbrandt J, Johnson EM, Jr. GFRalpha-mediated localization of RET to lipid rafts is required for effective downstream signaling, differentiation, and neuronal survival. Neuron. 2000;25(3):611-23.

18. Barlow A, de Graaff E, Pachnis V. Enteric nervous system progenitors are coordinately controlled by the $G$ protein-coupled receptor EDNRB and the receptor tyrosine kinase RET. Neuron. 2003;40(5):90516.

19. Bondurand N, Natarajan D, Barlow A, Thapar N, Pachnis V. Maintenance of mammalian enteric nervous system progenitors by SOX10 and endothelin 3 signalling. Development. 2006;133(10):2075-86.

20. Durbec PL, Larsson-Blomberg LB, Schuchardt A, Costantini F, Pachnis V. Common origin and developmental dependence on c-ret of subsets of enteric and sympathetic neuroblasts. Development. 1996;122(1):349-58.

21. Chalazonitis A, Rothman TP, Chen J, Gershon MD. Age-dependent differences in the effects of GDNF and NT-3 on the development of neurons and glia from neural crest-derived precursors immunoselected from the fetal rat gut: expression of GFRalpha-1 in vitro and in vivo. Developmental biology. 1998;204(2):385-406.

22. Payette RF, Tennyson VM, Pomeranz HD, Pham TD, Rothman TP, Gershon MD. Accumulation of components of basal laminae: association with the failure of neural crest cells to colonize the presumptive aganglionic bowel of Is/Is mutant mice. Developmental biology. 1988;125(2):341-60.

23. Chalazonitis A, Tennyson VM, Kibbey MC, Rothman TP, Gershon MD. The alpha1 subunit of laminin-1 promotes the development of neurons by interacting with LBP110 expressed by neural crest-derived cells immunoselected from the fetal mouse gut. Journal of neurobiology. 1997;33(2):118-38. 
24. Kurihara Y, Kurihara H, Oda H, Maemura K, Nagai R, Ishikawa T, et al. Aortic arch malformations and ventricular septal defect in mice deficient in endothelin-1. The Journal of clinical investigation. 1995;96(1):293-300.

25. Clouthier DE, Hosoda K, Richardson JA, Williams SC, Yanagisawa H, Kuwaki T, et al. Cranial and cardiac neural crest defects in endothelin-A receptor-deficient mice. Development. 1998;125(5):81324.

26. Duess JW, Puri P. Syndromic Hirschsprung's disease and associated congenital heart disease: a systematic review. Pediatric surgery international. 2015;31(8):781-5.

27. Ida-Eto M, Ohgami N, lida M, Yajima I, Kumasaka MY, Takaiwa K, et al. Partial requirement of endothelin receptor $B$ in spiral ganglion neurons for postnatal development of hearing. The Journal of biological chemistry. 2011;286(34):29621-6.

28. Hua LL, Vedantham V, Barnes RM, Hu J, Robinson AS, Bressan M, et al. Specification of the mouse cardiac conduction system in the absence of Endothelin signaling. Developmental biology. 2014;393(2):245-54.

29. Pardono E, van Bever Y, van den Ende J, Havrenne PC, lughetti P, Maestrelli SR, et al. Waardenburg syndrome: clinical differentiation between types I and II. American journal of medical genetics Part A. 2003;117A(3):223-35.

30. Sandoval RL, Zaconeta CM, Margotto PR, Cardoso MT, Franca EM, Medina CT, et al. Congenital central hypoventilation syndrome associated with Hirschsprung's Disease: case report and literature review. Rev Paul Pediatr. 2016;34(3):374-8.

31. Davenport M, Taitz LS, Dickson JA. The Kaufman-McKusick syndrome: another association. Journal of pediatric surgery. 1989;24(11):1192-4.

32. Spouge D, Baird PA. Hirschsprung disease in a large birth cohort. Teratology. 1985;32(2):171-7.

33. Le Douarin N, Kalcheim C. The Neural Crest. 2 ed. Cambridge: Cambridge University Press; 1999.

34. Laurence KM, Prosser R, Rocker I, Pearson JF, Richard C. Hirschsprung's disease associated with congenital heart malformation, broad big toes, and ulnar polydactyly in sibs: a case for fetoscopy. Journal of medical genetics. 1975;12(4):334-8.

35. Parisi MA, Kapur RP. Genetics of Hirschsprung disease. Current opinion in pediatrics. 2000;12(6):6107.

36. Rosenthal A. The GDNF protein family: gene ablation studies reveal what they really do and how. Neuron. 1999;22(2):201-3.

37. Hofstra RM, Valdenaire O, Arch E, Osinga J, Kroes H, Loffler BM, et al. A loss-of-function mutation in the endothelin-converting enzyme 1 (ECE-1) associated with Hirschsprung disease, cardiac defects, and autonomic dysfunction. American journal of human genetics. 1999;64(1):304-8.

38. Wu TT, Tsai TW, Chu CT, Lee ZF, Hung CM, Su CC, et al. Low RET mutation frequency and polymorphism analysis of the RET and EDNRB genes in patients with Hirschsprung disease in Taiwan. J Hum Genet. 2005;50(4):168-74. 
39. Garcia-Barcelo M, Sham MH, Lee WS, Lui VC, Chen BL, Wong KK, et al. Highly recurrent RET mutations and novel mutations in genes of the receptor tyrosine kinase and endothelin receptor $B$ pathways in Chinese patients with sporadic Hirschsprung disease. Clin Chem. 2004;50(1):93-100.

40. Kim JH, Yoon KO, Kim H, Kim JK, Kim JW, Lee SK, et al. New variations of the EDNRB gene and its association with sporadic Hirschsprung's disease in Korea. Journal of pediatric surgery. 2006;41(10):1708-12.

41. Puffenberger EG, Hosoda K, Washington SS, Nakao K, deWit D, Yanagisawa M, et al. A missense mutation of the endothelin-B receptor gene in multigenic Hirschsprung's disease. Cell. 1994;79(7):1257-66.

42. Davenport AP. International Union of Pharmacology. XXIX. Update on endothelin receptor nomenclature. Pharmacological reviews. 2002;54(2):219-26.

43. Yanagisawa $M$, Kurihara $H$, Kimura S, Tomobe $Y$, Kobayashi M, Mitsui $Y$, et al. A novel potent vasoconstrictor peptide produced by vascular endothelial cells. Nature. 1988;332(6163):411-5.

44. Barnes K, Turner AJ. The endothelin system and endothelin-converting enzyme in the brain: molecular and cellular studies. Neurochemical research. 1997;22(8):1033-40.

45. Kedzierski RM, Yanagisawa M. Endothelin system: the double-edged sword in health and disease. Annual review of pharmacology and toxicology. 2001;41:851-76.

46. Hosoda K, Hammer RE, Richardson JA, Baynash AG, Cheung JC, Giaid A, et al. Targeted and natural (piebald-lethal) mutations of endothelin-B receptor gene produce megacolon associated with spotted coat color in mice. Cell. 1994;79(7):1267-76.

47. Webb DJ, Monge JC, Rabelink TJ, Yanagisawa M. Endothelin: new discoveries and rapid progress in the clinic. Trends in pharmacological sciences. 1998;19(1):5-8.

48. Arai H, Hori S, Aramori I, Ohkubo H, Nakanishi S. Cloning and expression of a cDNA encoding an endothelin receptor. Nature. 1990;348(6303):730-2.

49. Bacon CR, Cary NR, Davenport AP. Endothelin peptide and receptors in human atherosclerotic coronary artery and aorta. Circ Res. 1996;79(4):794-801.

50. Seo B, Oemar BS, Siebenmann R, von Segesser L, Luscher TF. Both ETA and ETB receptors mediate contraction to endothelin-1 in human blood vessels. Circulation. 1994;89(3):1203-8.

51. Adner M, Geary GG, Edvinsson L. Appearance of contractile endothelin-B receptors in rat mesenteric arterial segments following organ culture. Acta physiologica Scandinavica. 1998;163(2):121-9.

52. Pollock DM, Portik-Dobos V, Procter C, Gariepy CE, Yanagisawa M. Arterial pressure response to endothelin-1 and sarafotoxin $6 \mathrm{c}$ in rescued endothelin-B-deficient rats. Journal of cardiovascular pharmacology. 2000;36(5 Suppl 1):S82-5.

53. Saetrum Opgaard O, Adner M, Peters TH, Xu CB, Stavenow L, Gulbenkian S, et al. Endocardial expression and functional characterization of endothelin-1. Mol Cell Biochem. 2001;224(1-2):151-8.

54. Wagner OF, Christ G, Wojta J, Vierhapper H, Parzer S, Nowotny PJ, et al. Polar secretion of endothelin1 by cultured endothelial cells. The Journal of biological chemistry. 1992;267(23):16066-8. 
55. Hirata Y, Emori T, Eguchi S, Kanno K, Imai T, Ohta K, et al. Endothelin receptor subtype B mediates synthesis of nitric oxide by cultured bovine endothelial cells. The Journal of clinical investigation. 1993;91(4):1367-73.

56. Namiki A, Hirata Y, Ishikawa M, Moroi M, Aikawa J, Machii K. Endothelin-1- and endothelin-3-induced vasorelaxation via common generation of endothelium-derived nitric oxide. Life sciences. 1992;50(10):677-82.

57. de Nucci G, Thomas R, D'Orleans-Juste P, Antunes E, Walder C, Warner TD, et al. Pressor effects of circulating endothelin are limited by its removal in the pulmonary circulation and by the release of prostacyclin and endothelium-derived relaxing factor. Proceedings of the National Academy of Sciences of the United States of America. 1988;85(24):9797-800.

58. Nilsson D, Wackenfors A, Gustafsson L, Ugander M, Paulsson P, Ingemansson R, et al. Endothelin receptor-mediated vasodilatation: effects of organ culture. European journal of pharmacology. 2008;579(1-3):233-40.

59. Mundhenke M, Schwartzkopff B, Kostering M, Deska U, Klein RM, Strauer BE. Endogenous plasma endothelin concentrations and coronary circulation in patients with mild dilated cardiomyopathy. Heart. 1999;81(3):278-84.

60. Neunteufl T, Berger R, Pacher R. Endothelin receptor antagonists in cardiology clinical trials. Expert opinion on investigational drugs. 2002;11(3):431-43.

61. Piuhola J, Makinen M, Szokodi I, Ruskoaho H. Dual role of endothelin-1 via ETA and ETB receptors in regulation of cardiac contractile function in mice. Am J Physiol Heart Circ Physiol. 2003;285(1):H112-8.

62. Skovsted GF, Kruse LS, Larsen R, Pedersen AF, Trautner S, Sheykhzade M, et al. Heart ischaemiareperfusion induces local up-regulation of vasoconstrictor endothelin ETB receptors in rat coronary arteries downstream of occlusion. Br J Pharmacol. 2014;171(11):2726-38.

63. Gariepy CE, Cass DT, Yanagisawa M. Null mutation of endothelin receptor type B gene in spotting lethal rats causes aganglionic megacolon and white coat color. Proceedings of the National Academy of Sciences of the United States of America. 1996;93(2):867-72.

64. Chen KC AA, Song ZM, Croaker DG. High-Definition Heart Visualization using Micro-CT Scanning on Experimental Rats. J Clin Exp Cardiolog. 2018;9(606).

65. Schambach SJ, Bag S, Schilling L, Groden C, Brockmann MA. Application of micro-CT in small animal imaging. Methods. 2010;50(1):2-13.

66. Wilkins SW, Gureyev TE, Gao D, Pogany A, Stevenson AW. Phase-contrast imaging using polychromatic hard X-rays. Nature. 1996;384(6607):335-8.

67. Bradley RS, McNeil A, Withers PJ. An examination of phase retrieval algorithms as applied to phase contrast tomography using laboratory sources. Proc Spie. 2010;7804.

68. Limaye A. Drishti, A volume exploration and Presentation Tool. Developments in X-Ray Tomography VIII; 17 October 20122012. 
69. Schindelin J, Arganda-Carreras I, Frise E, Kaynig V, Longair M, Pietzsch T, et al. Fiji: an open-source platform for biological-image analysis. Nat Meth. 2012;9(7):676-82.

70. Buades A, Coll B, Morel J-M. A Non-Local Algorithm for Image Denoising. Proceedings of the 2005 IEEE Computer Society Conference on Computer Vision and Pattern Recognition (CVPR'05) - Volume 2 - Volume 02. 1069066: IEEE Computer Society; 2005. p. 60-5.

71. Brennan A, Dean CH, Zhang AL, Cass DT, Mirsky R, Jessen KR. Endothelins Control the Timing of Schwann Cell Generation in Vitro and in Vivo. Developmental biology. 2000;227(2):545-57.

72. Pini Prato A, Rossi V, Mosconi M, Holm C, Lantieri F, Griseri P, et al. A prospective observational study of associated anomalies in Hirschsprung's disease. Orphanet journal of rare diseases. 2013;8:184.

73. Croaker GDH. Clinical and Molecular Biological Studies in Hirschsprung's Disease [Doctoral thesis, University of Sydney, Sydney, Australia]. University of Sydney: University of Sydney. ; 2002.

74. Creazzo TL, Godt RE, Leatherbury L, Conway SJ, Kirby ML. Role of cardiac neural crest cells in cardiovascular development. Annu Rev Physiol. 1998;60:267-86.

75. Schneider DJ, Moore JW. Patent ductus arteriosus. Circulation. 2006;114(17):1873-82.

76. Webb S, Qayyum SR, Anderson RH, Lamers WH, Richardson MK. Septation and separation within the outflow tract of the developing heart. Journal of anatomy. 2003;202(4):327-42.

77. Jiang $X$, Rowitch DH, Soriano P, McMahon AP, Sucov HM. Fate of the mammalian cardiac neural crest. Development. 2000;127(8):1607-16.

78. Brown CB, Feiner L, Lu MM, Li J, Ma X, Webber AL, et al. PlexinA2 and semaphorin signaling during cardiac neural crest development. Development. 2001;128(16):3071-80.

79. Engleka KA, Gitler AD, Zhang M, Zhou DD, High FA, Epstein JA. Insertion of Cre into the Pax3 locus creates a new allele of Splotch and identifies unexpected Pax3 derivatives. Developmental biology. 2005;280(2):396-406.

80. Stottmann RW, Choi M, Mishina Y, Meyers EN, Klingensmith J. BMP receptor IA is required in mammalian neural crest cells for development of the cardiac outflow tract and ventricular myocardium. Development. 2004;131(9):2205-18.

81. Bacon CR, Davenport AP. Endothelin receptors in human coronary artery and aorta. Br J Pharmacol. 1996;117(5):986-92.

82. Tirapelli CR, Casolari DA, Yogi A, Montezano AC, Tostes RC, Legros E, et al. Functional characterization and expression of endothelin receptors in rat carotid artery: involvement of nitric oxide, a vasodilator prostanoid and the opening of $\mathrm{K}+$ channels in ETB-induced relaxation. $\mathrm{Br} \mathrm{J}$ Pharmacol. 2005;146(6):903-12.

83. Gariepy CE, Ohuchi T, Williams SC, Richardson JA, Yanagisawa M. Salt-sensitive hypertension in endothelin-B receptor-deficient rats. The Journal of clinical investigation. 2000;105(7):925-33.

84. Domenech R, Macho P, Gonzalez R, Huidobro-Toro JP. Effect of endothelin on total and regional coronary resistance and on myocardial contractility. European journal of pharmacology. 1991;192(3):409-16. 
85. Larkin SW, Clarke JG, Keogh BE, Araujo L, Rhodes C, Davies GJ, et al. Intracoronary endothelin induces myocardial ischemia by small vessel constriction in the dog. The American journal of cardiology. 1989;64(14):956-8.

86. Davenport AP, Kuc RE, Maguire JJ, Harland SP. ETA receptors predominate in the human vasculature and mediate constriction. Journal of cardiovascular pharmacology. 1995;26 Suppl 3:S265-7.

87. Dembowski C, Hofmann P, Koch T, Kamrowski-Kruck H, Riedesel H, Krammer HJ, et al. Phenotype, intestinal morphology, and survival of homozygous and heterozygous endothelin B receptordeficient (spotting lethal) rats. Journal of pediatric surgery. 2000;35(3):480-8.

\section{Additional File Legends}

\section{Supplementary Figure 1: Stepwise structural shrinkages were associated with decreasing functional $\mathrm{ET}_{\underline{B}}$.}

Stepwise reduction in cardiac size was associated with decreasing $\mathrm{ET}_{\mathrm{B}}$ copies, with wild-type having largest heart and constituents, followed by heterozygotes in the middle, and $s / / s /$ having the smallest structures: whole heart $\left(55.83 \mathrm{~mm}^{3} ; 54.61 \mathrm{~mm}^{3} ; 39.81 \mathrm{~mm}^{3}\right), \mathrm{LV}\left(29.68 \mathrm{~mm}^{3} ; 27.66 \mathrm{~mm}^{3} ; 20.30 \mathrm{~mm}^{3}\right)$, RV $\left(22.19 \mathrm{~mm}^{3} ; 21.76 \mathrm{~mm}^{3} ; 15.04 \mathrm{~mm}^{3}\right)$, LA $\left(2.46 \mathrm{~mm}^{3} ; 2.35 \mathrm{~mm}^{3} ; 1.66 \mathrm{~mm}^{3}\right)$, and RA $\left(4.43 \mathrm{~mm}^{3} ; 4.23 \mathrm{~mm}^{3}\right.$; $3.11 \mathrm{~mm}^{3}$ ). The difference between wild-type and heterozygotes was relatively small whereas tissue shrinkages in $s / / s /$ rat were markedly larger. On the other hand, aortic arch measurements did not suggest gene-dose-dependency: wild-type $\left(1.39 \mathrm{~mm}^{3}\right)$, heterozygotes $\left(1.74 \mathrm{~mm}^{3}\right)$, and $s / / s /\left(1.29 \mathrm{~mm}^{3}\right)$.

$R A=$ Right Atrium; $R V=$ Right Ventricle; $L A=L$ eft Atrium; $L V=L$ eft Ventricle.

*: statistically significant in comparison to $E T_{B}{ }^{--}$group, $p \leq 0.05$.

\section{Supplementary Figure 2: Stepwise growth rate reduction was associated with decreasing functional $\mathrm{ET}_{\underline{B}}$.}

Stepwise decrease in cardiac growth rates corresponded to reducing $\mathrm{ET}_{\mathrm{B}}$ copies. As shown, wild-type has highest growth rates, followed by heterozygotes in the middle, and lowest in $s / / s /$ rat: whole heart $\left(0.61 \mathrm{~mm}^{3} / \mathrm{Hr} ; 0.57 \mathrm{~mm}^{3} / \mathrm{Hr} ; 0.48 \mathrm{~mm}^{3} / \mathrm{Hr}\right), \mathrm{LV}\left(0.33 \mathrm{~mm}^{3} / \mathrm{Hr} ; 0.29 \mathrm{~mm}^{3} / \mathrm{Hr} ; 0.24 \mathrm{~mm}^{3} / \mathrm{Hr}\right), \mathrm{RV}\left(0.24 \mathrm{~mm}^{3} / \mathrm{Hr}\right.$; $\left.0.23 \mathrm{~mm}^{3} / \mathrm{Hr} ; 0.18 \mathrm{~mm}^{3} / \mathrm{Hr}\right), \mathrm{LA}\left(0.027 \mathrm{~mm}^{3} / \mathrm{Hr} ; 0.024 \mathrm{~mm}^{3} / \mathrm{Hr} ; 0.020 \mathrm{~mm}^{3} / \mathrm{Hr}\right)$, and RA $\left(0.049 \mathrm{~mm}^{3} / \mathrm{Hr}\right.$; $0.044 \mathrm{~mm}^{3} / \mathrm{Hr} ; 0.038 \mathrm{~mm}^{3} / \mathrm{Hr}$ ). Wild-type and heterozygotes have relatively small growth rate variations when comparing their respective differences to $s / / s /$ rat. No consistent correlations with genotype can be deduced from aortic arch measurements: wild-type $\left(0.015 \mathrm{~mm}^{3} / \mathrm{Hr}\right)$, heterozygotes $\left(0.018 \mathrm{~mm}^{3} / \mathrm{Hr}\right)$, and $s / / s l\left(0.015 \mathrm{~mm}^{3} / \mathrm{Hr}\right)$.

$R A=$ Right Atrium; $R V=$ Right Ventricle; $L A=L$ eft Atrium; $L V=L$ eft Ventricle.

*: statistically significant in comparison to $E T_{B}{ }^{-/}$group, $p \leq 0.05$. 
Supplementary Figure 3: stepwise reduction in organ/bodyweight ratio associated with decreasing copies of functional $\mathrm{ET}_{\underline{B}}$.

Positive correlations between cardiac organ/bodyweight indices and $\mathrm{ET}_{\mathrm{B}}$ gene copy was demonstrated. Wild-type has the highest ratio, followed by heterozygotes in the middle, and $s / / s /$ having the lowest: whole heart $\left(4.31 \mathrm{~mm}^{3} / \mathrm{g} ; 4.00 \mathrm{~mm}^{3} / \mathrm{g} ; 3.46 \mathrm{~mm}^{3} / \mathrm{g}\right), \mathrm{LV}\left(2.30 \mathrm{~mm}^{3} / \mathrm{g} ; 2.02 \mathrm{~mm}^{3} / \mathrm{g} ; 1.77 \mathrm{~mm}^{3} / \mathrm{g}\right), \mathrm{RV}$ $\left(1.71 \mathrm{~mm}^{3} / \mathrm{g} ; 1.59 \mathrm{~mm}^{3} / \mathrm{g} ; 1.31 \mathrm{~mm}^{3} / \mathrm{g}\right)$, LA $\left(0.19 \mathrm{~mm}^{3} / \mathrm{g} ; 0.17 \mathrm{~mm}^{3} / \mathrm{g} ; 0.14 \mathrm{~mm}^{3} / \mathrm{g}\right)$, and RA $\left(0.34 \mathrm{~mm}^{3} / \mathrm{g}\right.$; $0.31 \mathrm{~mm}^{3} / \mathrm{g} ; 0.27 \mathrm{~mm}^{3} / \mathrm{g}$ ). Minor difference was presented between wild-type and heterozygote when comparing to the reductions observed in $s / / s /$ rats. In conjunction with Figure 1 , this supported $\mathrm{ET}_{\mathrm{B}}$ mutation has intrinsic effect on cardiac development. No consistent trend associating with genotype can be deduced from aortic arch measurements: wild-type $\left(0.11 \mathrm{~mm}^{3} / \mathrm{g}\right)$, heterozygotes $\left(0.13 \mathrm{~mm}^{3} / \mathrm{g}\right)$, and $s / / s /\left(0.11 \mathrm{~mm}^{3} / \mathrm{g}\right)$.

$R A=$ Right Atrium; $R V=$ Right Ventricle; $L A=L$ eft Atrium; $L V=L$ eft Ventricle.

*: statistically significant in comparison to $E T_{B}{ }^{--}$group, $p \leq 0.05$.

\section{Supplementary Table 1: sl/s/ rat has reduced luminal width of aortic arch when comparing to the control groups.}

Two-dimensional measurement at the entry of aortic valve showed $s / / s /$ rat having smaller intravascular width comparing to the control group. This trend persisted when respective age and bodyweight were standardized, as shown by the comparison of width growth-rate and width/bodyweight ratio, suggesting possible vasoconstriction.

\section{Figures}




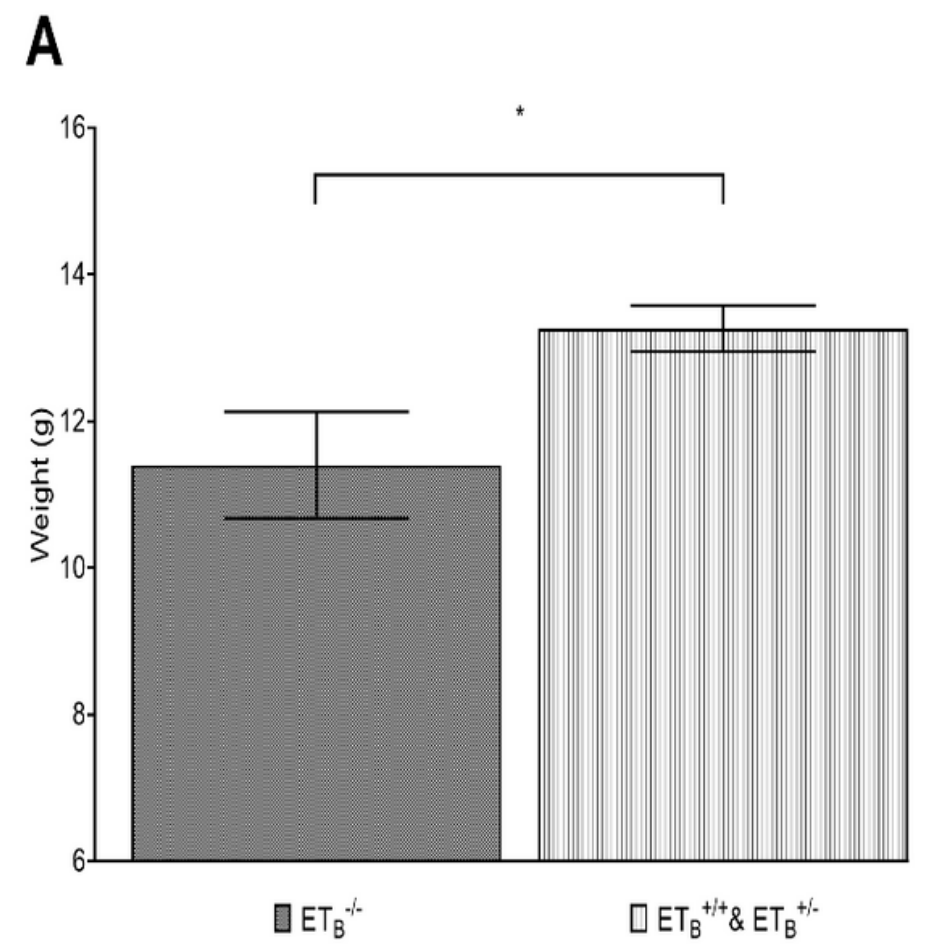

B

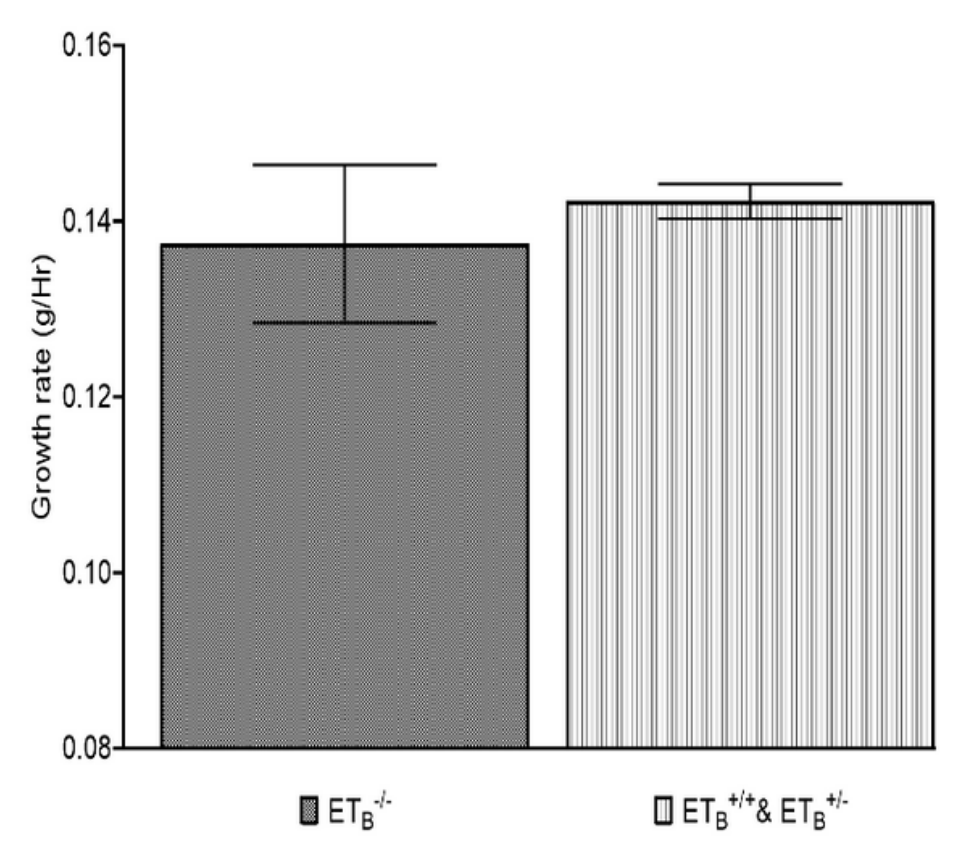

Figure 1

Decreases in bodyweight (A) and body-growth rates (B) in sl/sl rat. Figure $1 \mathrm{~A}$ showed sl/sl (ETB-/-) rats having statistically significant smaller bodyweight than the control group $(E T B+/+\& E T B+/-), 11.40 \mathrm{~g}$ versus $13.26 \mathrm{~g}$, $\mathrm{p}$-value $=0.03$. However, when corrected with respective age $(\mathrm{Hr})$, smaller difference was observed between the two groups, $0.137 \mathrm{~g} / \mathrm{Hr}$ versus $0.142 \mathrm{~g} / \mathrm{Hr}$, p-value $=0.58$. ETB- $/$ - induced global growth impairment was likely small in the early stage of development. *: statistically significant, $p$-value < 0.05 . 


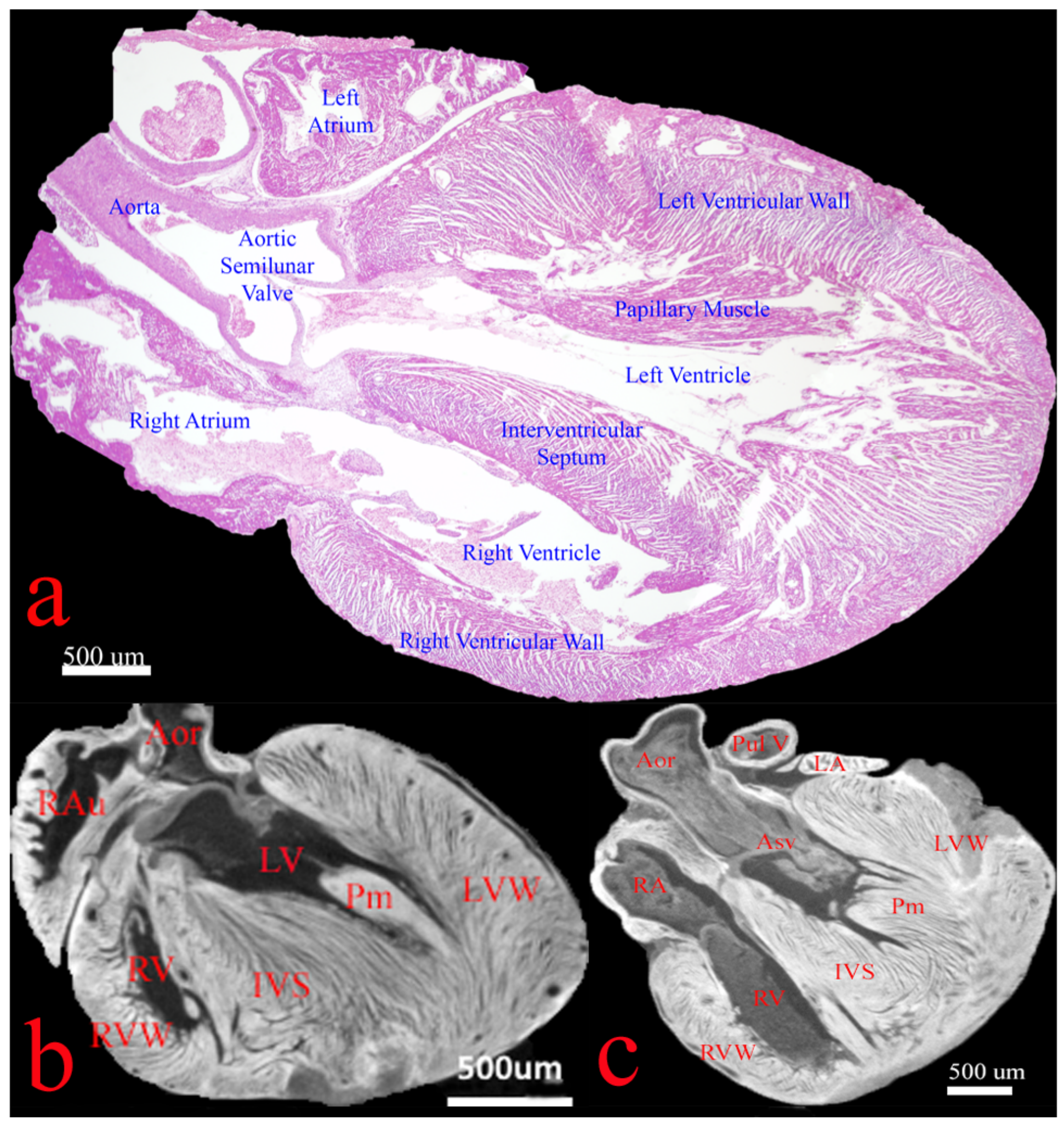

Figure 2

Grossly normal cardiac morphology and constituents in sl/sl rat. Figure 2A (4x H\&E microscopy), 2B, and $2 \mathrm{C}$ (ex vivo micro-CT, $10.7 \mu \mathrm{m} / \mathrm{voxel}$ ) were cardiac illustrations sl/sl rats in coronal views. No detectable gross abnormality was identified. Both image types showed patent cardiac outflow tract with fully formed atria and ventricles. Septal defects were not detected. Major structures were as labelled. Aor=Aorta; RAu=Right Auricle; RA=Right Atrium; RV=Right Ventricle; RVW=Right Ventricular Wall; IVS=Interventricular 
Septum; LA=Left Atrium; LV=Left Ventricle; LVW=Left Ventricular Wall; Pm=Papillary Muscle; Pul V=Pulmonary Vessel; Asv=Aortic semilunar valve.

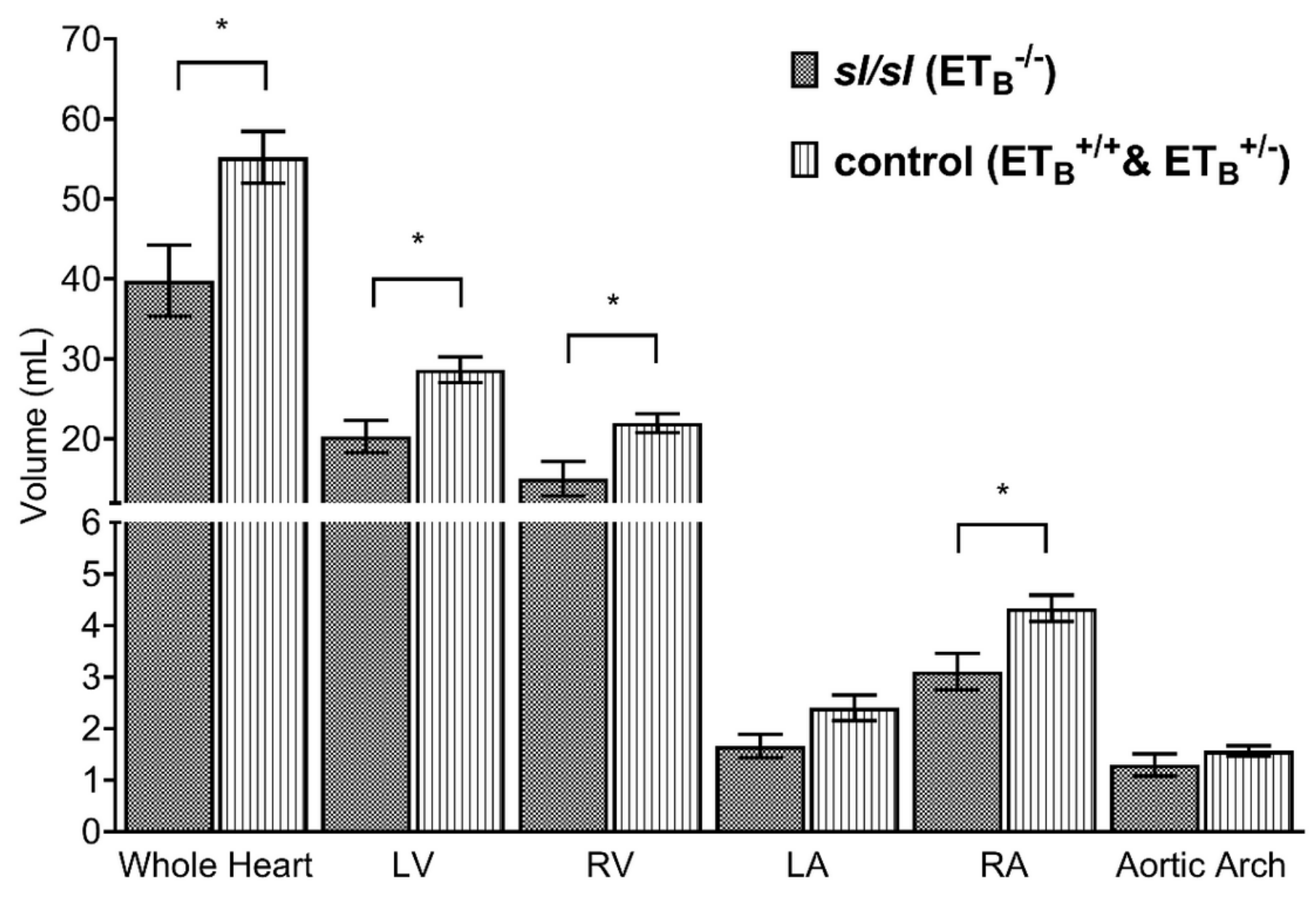

Figure 3

$\mathrm{sl} / \mathrm{sl}$ rat has significantly smaller cardiac structures. $\mathrm{sl} / \mathrm{sl}$ rat has a smaller heart when comparing to the control animals, $39.81 \mathrm{~mm} 3$ versus $55.22 \mathrm{~mm} 3, \mathrm{p}$-value $=0.02$. Analyses on heart constituents showed similar trend: LV $(20.30 \mathrm{~mm} 3$ versus $28.67 \mathrm{~mm} 3$, $p$-value $=0.01), \mathrm{RV}(15.04 \mathrm{~mm} 3$ versus $21.98 \mathrm{~mm} 3, \mathrm{p}$ value $=0.02)$, LA $(1.66 \mathrm{~mm} 3$ versus $2.40 \mathrm{~mm} 3, \mathrm{p}$-value $=0.06)$, and $R A(3.11 \mathrm{~mm} 3$ versus $4.33 \mathrm{~mm} 3, \mathrm{p}$ value $=0.02$ ). Minor volumetric difference in aortic arch was also detected between $\mathrm{sl} / \mathrm{sl}$ and the control group: $1.29 \mathrm{~mm} 3$ versus $1.56 \mathrm{~mm} 3, \mathrm{p}$-value $=0.25$. RA=Right Atrium; $R V=$ Right Ventricle; $L A=L$ eft Atrium; LV=Left Ventricle. *: statistically significant, $p$-value $<0.05$. 


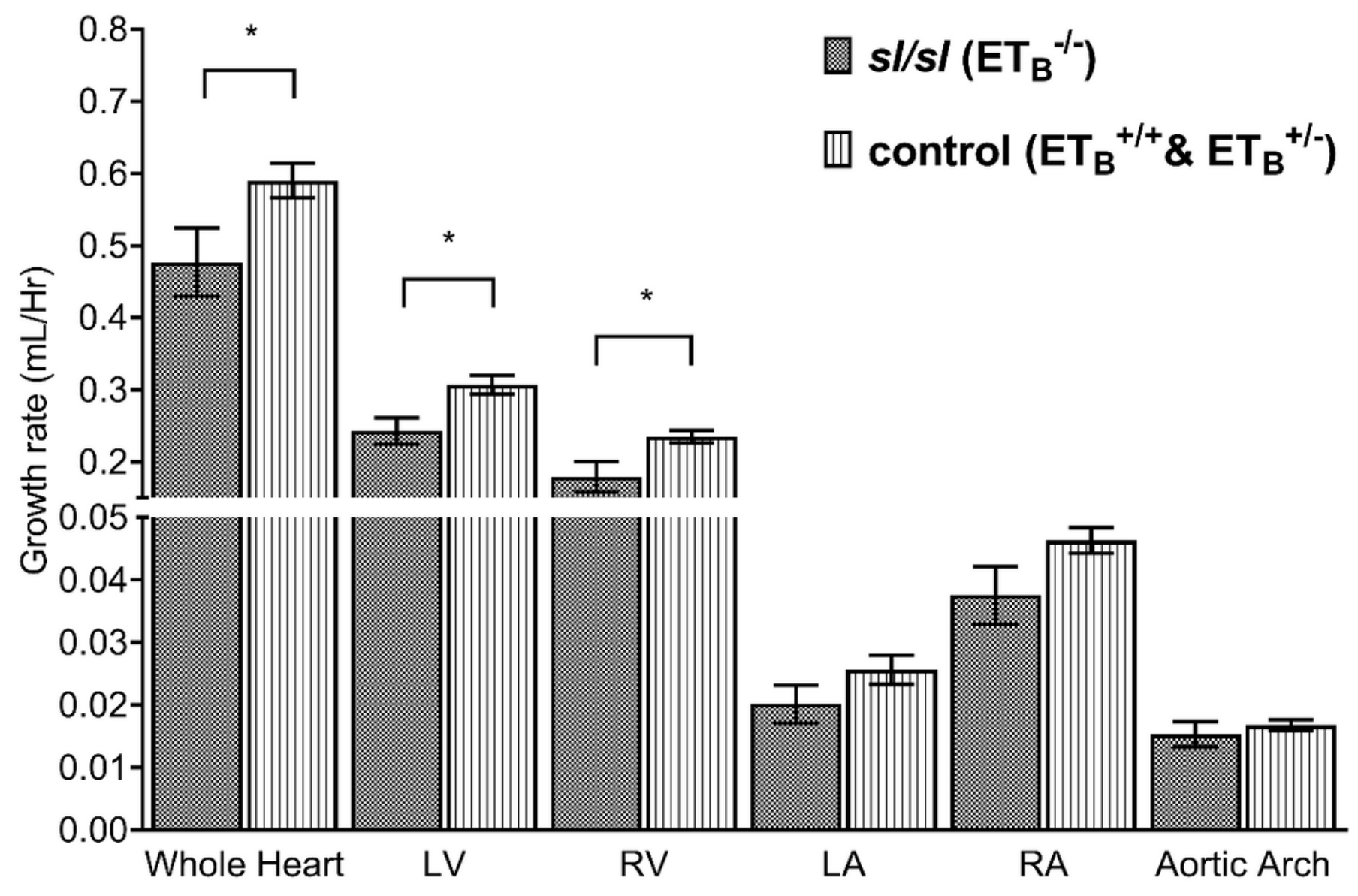

Figure 4

$\mathrm{sl} / \mathrm{sl}$ rat has lower cardiac growth rates than the control group. Markedly lower cardiac growth rate was detected in sl/sl rat with respect to the control animal, $0.48 \mathrm{~mm} 3 / \mathrm{Hr}$ versus $0.59 \mathrm{~mm} 3 / \mathrm{Hr}$, $\mathrm{p}$-value $=0.05$. Similar difference was observed between the two groups in LV $(0.24 \mathrm{~mm} 3 / \mathrm{Hr}$ versus $0.31 \mathrm{~mm} 3 / \mathrm{Hr}$, p-value $=0.02)$ and $\mathrm{RV}(0.18 \mathrm{~mm} 3 / \mathrm{Hr}$ versus $0.23 \mathrm{~mm} 3 / \mathrm{Hr}$, p-value $=0.03)$. Albeit not reaching statistical power, decreasing trend was also seen in $\mathrm{LA}(0.020 \mathrm{~mm} 3 / \mathrm{Hr}$ versus $0.026 \mathrm{~mm} 3 / \mathrm{Hr}$, p-value $=0.18)$ and $R A$ $(0.038 \mathrm{~mm} 3 / \mathrm{Hr}$ versus $0.046 \mathrm{~mm} 3 / \mathrm{Hr}$, p-value $=0.10)$. Aortic arch measurement showed little difference between the two groups: $0.015 \mathrm{~mm} 3 / \mathrm{Hr}$ versus $0.017 \mathrm{~mm} 3 / \mathrm{Hr}$, $\mathrm{p}$-value $=0.51$. RA=Right Atrium; RV=Right Ventricle; LA=Left Atrium; LV=Left Ventricle. *: statistically significant, $p$-value $<0.05$. 


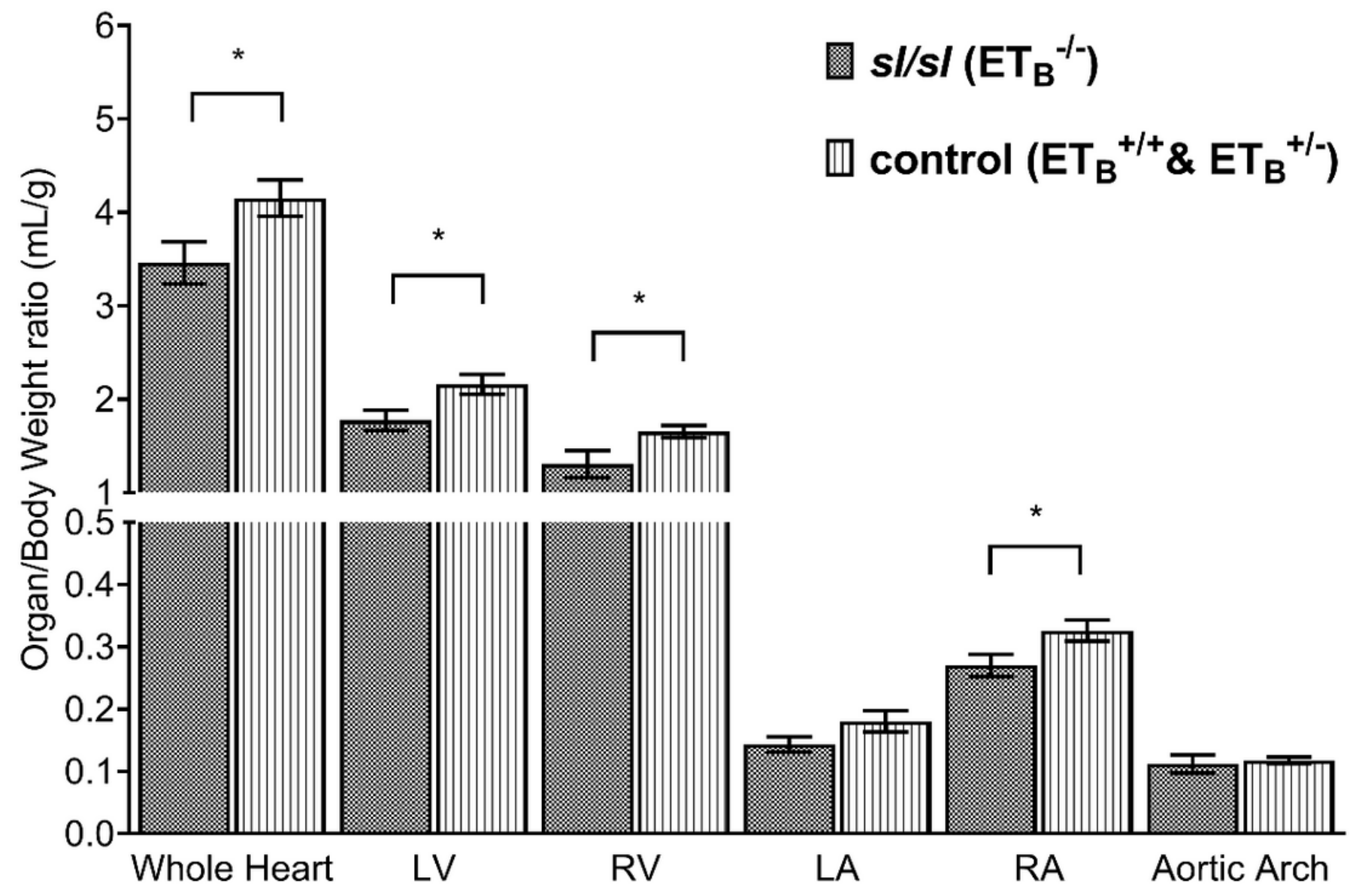

Figure 5

$\mathrm{sl} / \mathrm{sl}$ rat has disproportionally larger reductions in its heart size with respect to its bodyweight. Markedly smaller cardiac-organ/bodyweight ratios were observed in $\mathrm{sl} / \mathrm{sl}$ rat when comparing to those of control group: whole heart $(3.46 \mathrm{~mL} / \mathrm{g}$ versus $4.15 \mathrm{~mL} / \mathrm{g}$, $\mathrm{p}$-value $=0.04), \mathrm{LV}(1.77 \mathrm{~mL} / \mathrm{g}$ versus $2.16 \mathrm{~mL} / \mathrm{g}$, $\mathrm{p}$-value $=0.03), \mathrm{RV}(1.31 \mathrm{~mL} / \mathrm{g}$ versus $1.65 \mathrm{~mL} / \mathrm{g}, \mathrm{p}$-value $=0.04), \mathrm{LA}(0.14 \mathrm{~mL} / \mathrm{g}$ versus $0.18 \mathrm{~mL} / \mathrm{g}, \mathrm{p}$-value $=0.13)$, and $\mathrm{RA}(0.27 \mathrm{~mL} / \mathrm{g}$ versus $0.33 \mathrm{~mL} / \mathrm{g}$, $\mathrm{p}$-value $=0.049)$. This trend reflected disproportionally larger structural impairment in $\mathrm{sl} / \mathrm{sl}$ heart with respect to global growth restriction, supporting an intrinsic effect of ETB on heart growth. On the contrary, measurement on aortic arch showed little difference between the two groups: $0.112 \mathrm{~mL} / \mathrm{g}$ versus $0.118 \mathrm{~mL} / \mathrm{g}$, $p$-value $=0.70$. $R A=$ Right Atrium; $R V=$ Right Ventricle; $L A=L$ eft Atrium; LV=Left Ventricle. *: statistically significant in comparison to ETB -/- group, $p<0.05$. 


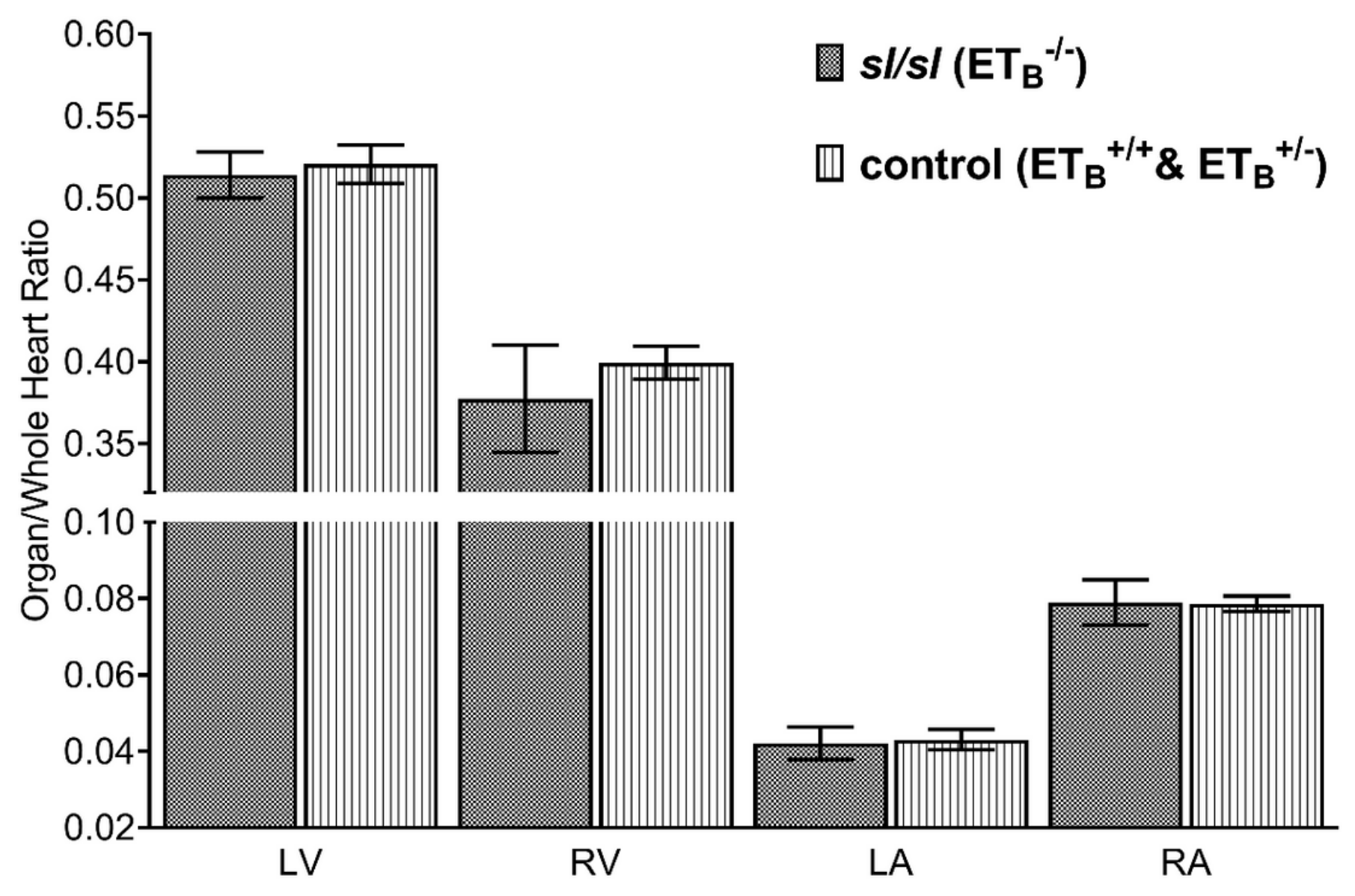

Figure 6

Cardiac shrinkage in $\mathrm{sl} / \mathrm{sl}$ rat was relatively uniform across four major constituents. No significant difference was detected in cardiac constituent/whole heart ratios between sl/sl and the control group. Both shared similar organ/whole heart ratios: $\mathrm{LV}(0.51$ vs 0.52 , $\mathrm{p}$-value $=0.72), \mathrm{RV}(0.38$ versus $0.40, \mathrm{p}$ value $=0.50)$, LA $(0.042$ versus 0.043 , $p$-value $=0.95)$, and RA $(0.079$ versus 0.079 , $p$-value $=0.95)$. This reflects ETB effect was overall uniform across all heart structures, albeit minor regional-dependent impact might be present in RV.

\section{Supplementary Files}

This is a list of supplementary files associated with this preprint. Click to download.

- SupplementaryTable1.docx

- ARRIVEGuidelinesChecklist10062020.pdf

- SupplementaryFigure2.tif

- SupplementaryFigure1.tif

- SupplementaryFigure3.tif 